Proceedings of the Online Conference "Applications of Physics in Mechanical and Material Engineering"

\title{
Structure and Properties of FeCoNCuB Nanocrystalline Alloys
}

\author{
K. JEZ̈* \\ Department of Physics, Częstochowa University of Technology, \\ al. Armii Krajowej 19, 42-200 Częstochowa, Poland \\ Doi: 10.12693/APhysPolA.139.499 \\ *e-mail: kingagagor@o2.pl
}

\begin{abstract}
This paper presents the results of research on the structure of bulk rapidly-cooled alloys. The investigated alloys, with the general formula: $\mathrm{Fe}_{45+x} \mathrm{Co}_{25-x} \mathrm{Nb}_{9} \mathrm{Cu}_{1} \mathrm{~B}_{20}$, were produced using the injectioncasting method. The materials were produced in the form of two sets of rods with diameters of either $0.5 \mathrm{~mm}$ or $1 \mathrm{~mm}$. Structural studies confirmed that the alloys have a nanocrystalline structure. The following crystalline phases were identified within the volume of the alloys: $\alpha$-Fe, $\mathrm{Fe}_{23} \mathrm{~B}_{6}$ and $\mathrm{Co}_{23} \mathrm{~B}_{6}$, with the last two phases mixed with each other. Additionally, in the alloy samples with a diameter of $1 \mathrm{~mm}$, an unidentified crystalline phase was formed during the solidification process. The magnetic properties of the alloys were determined on the basis of measurements associated with their primary magnetisation curves and static magnetic hysteresis loops. It was found that the addition of $\mathrm{Fe}$, at the expense of Co, reduces the value of the coercive field. Moreover, the $1 \mathrm{~mm}$ diameter alloy samples were found to exhibit inferior soft magnetic properties, compared to the $0.5 \mathrm{~mm}$ diameter samples. The higher value of the coercivity field, determined for the $\mathrm{Fe}_{45} \mathrm{Co}_{25} \mathrm{Nb}_{9} \mathrm{Cu}_{1} \mathrm{~B}_{20}$ alloy, is believed to be associated with the presence of residual ordering with hard magnetic properties. For the investigated alloy samples, the process of magnetisation in strong magnetic fields is associated with the suppression of thermally-excited spin-waves.
\end{abstract}

topics: rapidly-quenched alloys, nanocrystalline alloys, X-ray diffractometry, $\mathrm{Fe}_{23} \mathrm{~B}_{6}$, injection-casting method

\section{Introduction}

A sufficiently high cooling rate enables an alloy to solidify without undergoing a crystallisation process, and this allows a structure with a longrange atomic disorder to be obtained. The first amorphous alloys were produced in the 1950s and 1960s [1]. Over the years, amorphous alloys have been studied intensively, resulting in the development of new production methods and compositions. In the 1960s and 1970s, alloys with an amorphous structure and thickness of several millimetres were obtained [2]. Subsequent studies have shown that the ability of the alloy to glass-transition is related to the melt viscosity [3]. An appropriate selection of the chemical composition allows a disordered structure to be obtained for many different chemical compositions.

Alloys based on Fe and Co make up an important sub-group of the amorphous alloys $[4,5]$. They often exhibit better magnetic properties when compared with their crystalline counterparts. However, it has been proven in many studies that improved magnetic properties can be obtained by partial crystallisation of amorphous alloys [6-12]. Socalled nanocrystalline alloys are normally produced by the heat treatment of amorphous alloys. However, this process is time-consuming and difficult to arrange. Partially crystallised alloys can be obtained in a single-step process [13-17]. An appropriate selection of production parameters and chemical composition allows desired crystalline phases and good magnetic properties to be obtained.

As part of this described work, nanocrystalline rapidly-cooled alloys were produced in a singlestage production process. The aim of the work was to investigate the effects of the chemical composition and the diameter of the produced alloys on their resulting structural and magnetic properties.

\section{Experimental procedure}

Investigated polycrystalline ingots of $\mathrm{Fe}_{45+x} \mathrm{Co}_{25-x} \mathrm{Nb}_{9} \mathrm{Cu}_{1} \mathrm{~B}_{20}$ alloys, where $x=0$ or 5 , were produced inside an arc furnace. Five-gram melts were made, using components with a $99.9 \%$ purity and weighed to an accuracy of $0.0001 \mathrm{~g}$. The melting process was carried out on a water-cooled copper plate. Each batch was melted three times on each side in order to obtain a homogeneous structure. During the ingot manufacturing process, a titanium getter was melted in order to trap any impurities remaining in the furnace chamber. The manufacturing process was carried out under a protective argon atmosphere. The resulting ingots were mechanically cleaned, divided into 
smaller pieces and cleaned in an ultrasonic cleaner. The desired rapidly-cooled alloy samples were produced using an injection-casting method. Each polycrystalline charge was placed in a quartz crucible with a $1 \mathrm{~mm}$ diameter hole. The crucible was mounted in the working chamber in such a way that the alloy was supported inside a copper coil. The charge was melted using induction heating by passing a current of $10 \mathrm{~A}$ through the coil. The liquid melt was forced, under $0.1 \mathrm{MPa}$ argon pressure, into a water-cooled copper mould. The production process was carried out under the same conditions as for the production of the ingots. Rod-shaped alloy samples were cast with selected diameters of $0.5 \mathrm{~mm}$ and $1 \mathrm{~mm}$.

The structure of the produced alloys was investigated by using X-ray diffraction. This was carried out using a BRUKER D8 Advance X-ray diffractometer. Measurements were carried out on powdered samples in the two theta range of $30^{\circ}-100^{\circ}$. The pulverisation of the alloy samples was carried out under toluene in an agate mortar, thus preventing the crystallisation of the material.

Static magnetic hysteresis loops and primary magnetisation curves were measured for the samples by using a LakeShore vibration magnetometer. Measurements were carried out in the range of external magnetic field from 0 to $2 \mathrm{~T}$.

The primary magnetisation curves were subjected to numerical analysis. The spin-wave stiffness parameter $D_{\text {spf }}$ was determined by applying:

$$
D_{\mathrm{spf}}=\frac{1}{3} S J_{\mathrm{ex}}(a) a^{2} z_{m}
$$

where $S$ - the spin value in the distance from the central atom, $J_{e x}$ - the local exchange integral, $a$ - the distance to the nearest-neighbour atoms, $z_{m}$ - the number of nearest-neighbour magnetic atoms. In fact, $D_{\text {spf }}$ is connected with the changes in the nearest neighbourhood of the iron atoms.

\section{Results}

Diffractograms measured for the alloys in the state after solidification are given in Fig. 1.

The X-ray diffraction images show wide peaks in the range of $40-50^{\circ}$ two theta angle. This maximum is known as the amorphous halo and is related to the reflection of X-rays from randomly arranged atoms within the sample volume. The diffractograms also show narrow peaks related to the presence of ordered phases. Detailed analysis of the diffraction patterns was performed using the Match! Software package. Crystalline phases were identified: $\alpha$-Fe as well as $\mathrm{Fe}_{23} \mathrm{~B}_{6}$ and $\mathrm{Co}_{23} \mathrm{~B}_{6}$, with some peaks for these two phases showing some angular shift.

The observed shift is related to the history of the formation of these phases: due to rapid cooling the phases are incomplete. During the solidification of the alloy the diffusion of atoms is significantly impeded, therefore the resulting phases

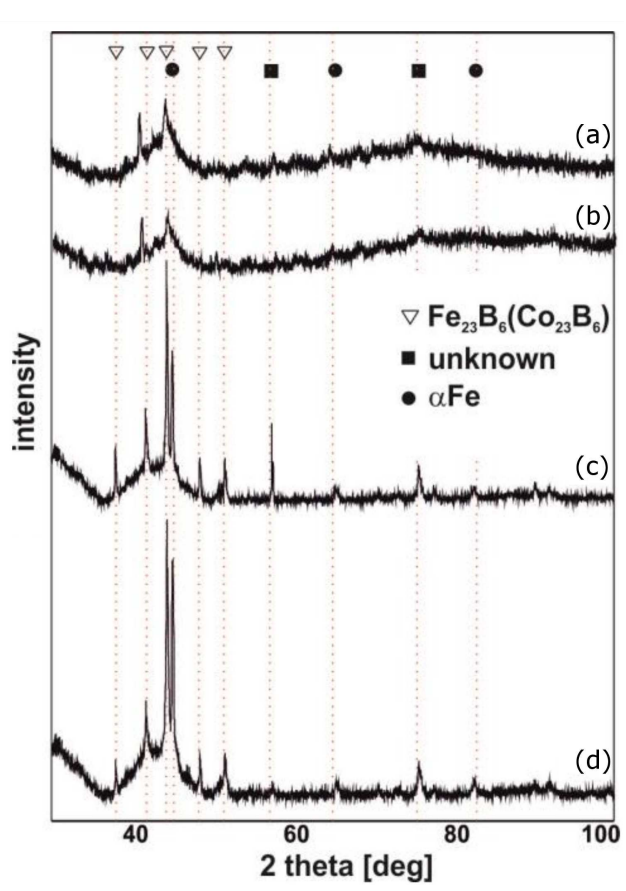

Fig. 1. X-ray diffraction patterns for the alloy samples: $0.5 \mathrm{~mm}$ rods: (a) $\mathrm{Fe}_{45} \mathrm{Co}_{25} \mathrm{Nb}_{9} \mathrm{Cu}_{1} \mathrm{~B}_{20}$, (b) $\mathrm{Fe}_{50} \mathrm{Co}_{20} \mathrm{Nb}_{9} \mathrm{Cu}_{1} \mathrm{~B}_{20} ; 1 \mathrm{~mm}$ rods: (c) $\mathrm{Fe}_{45} \mathrm{Co}_{25} \mathrm{Nb}_{9} \mathrm{Cu}_{1} \mathrm{~B}_{20}$, (d) $\mathrm{Fe}_{50} \mathrm{Co}_{20} \mathrm{Nb}_{9} \mathrm{Cu}_{1} \mathrm{~B}_{20}$.

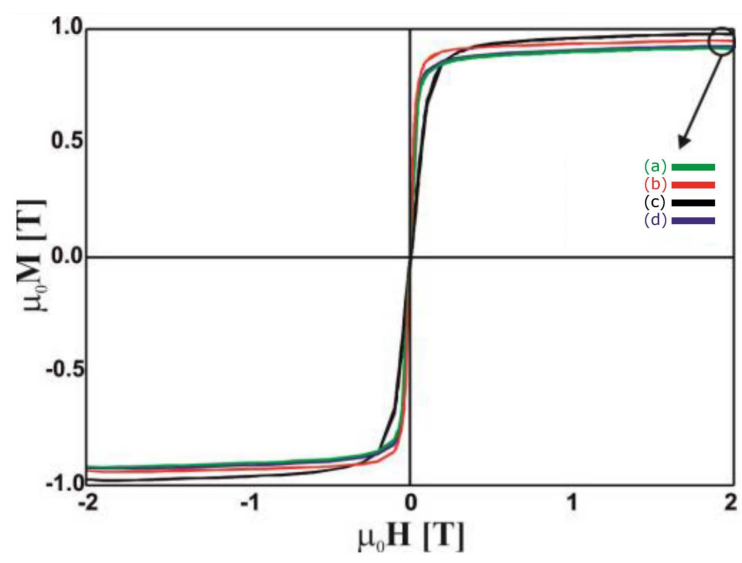

Fig. 2. Static magnetic hysteresis loops for the alloys: $0.5 \mathrm{~mm}$ rods: (a) $\mathrm{Fe}_{45} \mathrm{Co}_{25} \mathrm{Nb}_{9} \mathrm{Cu}_{1} \mathrm{~B}_{20}$, (b) $\mathrm{Fe}_{50} \mathrm{Co}_{20} \mathrm{Nb}_{9} \mathrm{Cu}_{1} \mathrm{~B}_{20} ; 1 \mathrm{~mm}$ rods: (c) $\mathrm{Fe}_{45} \mathrm{Co}_{25} \mathrm{Nb}_{9} \mathrm{Cu}_{1} \mathrm{~B}_{20}$, (d) $\mathrm{Fe}_{50} \mathrm{Co}_{20} \mathrm{Nb}_{9} \mathrm{Cu}_{1} \mathrm{~B}_{20}$.

may differ in the lattice constants and the relative positions of the atoms. For alloy samples with a diameter of $1 \mathrm{~mm}$, the peaks originating from crystalline phases are characterised by much higher intensity, which is obviously related to the longer solidification time of the alloy. In addition, the diffractograms have a peak near $55^{\circ}$ two theta that has not been associated with any crystalline phase. This peak is characterised by a significant intensity for the $\mathrm{Fe}_{45} \mathrm{Co}_{25} \mathrm{Nb}_{9} \mathrm{Cu}_{1} \mathrm{~B}_{20}$ alloy with a diameter of $1 \mathrm{~mm}$. Figure 2 shows the static magnetic hysteresis loops for the tested alloys. 


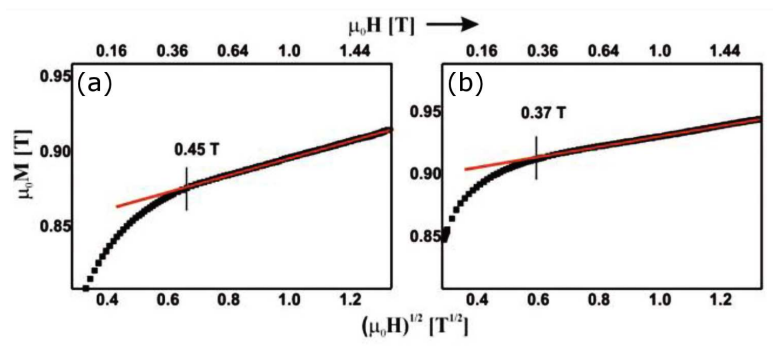

$\mu_{0} \mathrm{H}[\mathrm{T}] \longrightarrow$

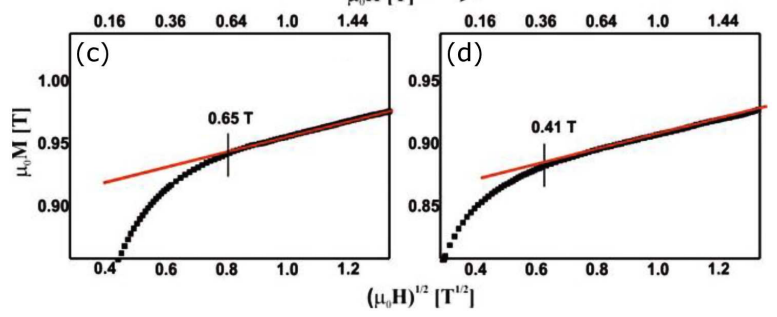

Fig. 3. Magnetisation as a function of $\left(\mu_{0} H\right)^{1 / 2}$ for the alloy samples: $0.5 \mathrm{~mm}$ rods: (a) $\mathrm{Fe}_{45} \mathrm{Co}_{25} \mathrm{Nb}_{9} \mathrm{Cu}_{1} \mathrm{~B}_{20}$, (b) $\mathrm{Fe}_{50} \mathrm{Co}_{20} \mathrm{Nb}_{9} \mathrm{Cu}_{1} \mathrm{~B}_{20}$; $1 \mathrm{~mm}$ rods: (c) $\mathrm{Fe}_{45} \mathrm{Co}_{25} \mathrm{Nb}_{9} \mathrm{Cu}_{1} \mathrm{~B}_{20}, \quad$ (d)

$\mathrm{Fe}_{50} \mathrm{Co}_{20} \mathrm{Nb}_{9} \mathrm{Cu}_{1} \mathrm{~B}_{20}$.

The static magnetic hysteresis loops have a general shape which is typical for soft magnetic materials. The loops for the alloy samples with a diameter of $0.5 \mathrm{~mm}$, and for the alloy $\mathrm{Fe}_{50} \mathrm{Co}_{20} \mathrm{Nb}_{9} \mathrm{Cu}_{1} \mathrm{~B}_{20}$ with a diameter of $1 \mathrm{~mm}$, have similar trajectories. In the case of the $\mathrm{Fe}_{45} \mathrm{Co}_{25} \mathrm{Nb}_{9} \mathrm{Cu}_{1} \mathrm{~B}_{20}$ alloy sample with a diameter of $1 \mathrm{~mm}$, the loop is clearly more deflected in the direction of the $\mu_{0} \mathrm{H}$ axis, which proves that the process of magnetising this alloy is relatively difficult. Values of saturation magnetisation $M_{S}$ and coercive field $H_{C}$ were measured from the course of the loop. These values are presented in Table I.

The primary magnetisation curves were subjected to numerical analysis. Figure 3 presents the magnetisation curves as a function of $\left(\mu_{0} H\right)^{1 / 2}$. The process of magnetisation of the tested alloy samples in high magnetic fields is related to the suppression of thermally-excited spin-waves. This phenomenon is called the Holstein-Primakoff paraprocess it describes the interactions between pairs of atoms with ferromagnetic properties [18]. Analysing the magnetisation curves in the area of paraprocess occurrence, the values of the $D_{\text {spf }}$ parameter were determined. These are presented in Table I. For the tested samples, there is a clear division arising from the structural and magnetic properties, according to the chemical composition and diameter of the samples produced.

Alloys with a higher content of $\mathrm{Fe}$, at the expense of Co, are characterised by much lower values of coercive field, and they achieve saturation at much lower values of external magnetic field intensity $(0.37 \mathrm{~T}$ and $0.41 \mathrm{~T})$. Based on the $\mathrm{X}$-ray diffraction patterns, it can be concluded that the alloys with a diameter of $0.5 \mathrm{~mm}$ are characterised
TABLE I

Magnetic properties of the $\mathrm{Fe}_{60} \mathrm{Co}_{10} \mathrm{Y}_{5+x} \mathrm{Zr}_{5-x} \mathrm{~B}_{20}$ alloys and the identified crystalline phases.

\begin{tabular}{c|c|c|c|c}
\hline \hline $\begin{array}{c}\text { diameter } \\
{[\mathrm{mm}]}\end{array}$ & Alloy & $\begin{array}{c}M_{S} \\
{[\mathrm{~T}]}\end{array}$ & $\begin{array}{c}H_{C} \\
{[\mathrm{~A} / \mathrm{m}]}\end{array}$ & $\begin{array}{c}D_{\text {spf }} \\
{\left[\mathrm{meV} \mathrm{nm}^{2}\right]}\end{array}$ \\
\hline 0.5 & $\mathrm{Fe}_{45} \mathrm{Co}_{25} \mathrm{Nb}_{9} \mathrm{Cu}_{1} \mathrm{~B}_{20}$ & 0.95 & 395 & 41 \\
0.5 & $\mathrm{Fe}_{50} \mathrm{Co}_{20} \mathrm{Nb}_{9} \mathrm{Cu}_{1} \mathrm{~B}_{20}$ & 0.92 & 95 & 42 \\
1 & $\mathrm{Fe}_{45} \mathrm{Co}_{25} \mathrm{Nb}_{9} \mathrm{Cu}_{1} \mathrm{~B}_{20}$ & 0.93 & 3400 & 42 \\
1 & $\mathrm{Fe}_{50} \mathrm{Co}_{20} \mathrm{Nb}_{9} \mathrm{Cu}_{1} \mathrm{~B}_{20}$ & 0.98 & 138 & 42
\end{tabular}

by a greater proportion of the amorphous phase as compared to the alloys with a diameter of $1 \mathrm{~mm}$. The smaller, i.e., $0.5 \mathrm{~mm}$ diameter alloy samples also have much lower values of coercive field.

\section{Conclusions}

The aim of this work was to determine the effect of the diameter of alloy samples, produced on the Fe and Co matrix, on the solidification process of rapidly-cooled alloy samples and the formation of a partially crystallised structure. Based on the X-ray diffraction patterns, it was found that the alloys are characterised by a nanocrystalline structure. The expected result is the achievement of a higher degree of crystallisation for larger diameter samples of the alloy, which is associated with a longer solidification time. In the case of the tested alloys, it was also found that the addition of $\mathrm{Fe}-$ at the expense of $\mathrm{Co}$ - reduces the value of the coercivity field. The tested alloys are characterised by soft magnetic properties, with the exception of the $\mathrm{Fe}_{45} \mathrm{Co}_{25} \mathrm{Nb}_{9} \mathrm{Cu}_{1} \mathrm{~B}_{20}$ alloy with a diameter of $1 \mathrm{~mm}$. In this latter case, the value of $H_{C}=3400 \mathrm{~A} / \mathrm{m}$ was recorded, which was related to the presence of an unidentified crystalline phase; in turn, this could be characterised by order which hinders the magnetisation process.

No relationship was observed between the chemical composition and the diameter of the samples and the value of saturation magnetisation and the $D_{\text {spf }}$ parameter.

\section{References}

[1] W. Klement, R.H. Willens, P. Duwez, $\mathrm{Na}$ ture 187, 869 (1960).

[2] H.S. Chen, D. Turnbull, Acta Metall. 17, 1021 (1969).

[3] A. Takeuchi, A. Inoue, Mater. Trans. 46, 2817 (2005).

[4] M.E. Mchenry, M.A. Willard, D.E. Laughlin, Prog. Mater. Sci. 44, 291 (1999).

[5] J. Gondro, K. Błoch, M. Nabiałek, S. Garus, Mater. Tehnol. 50, 559 (2016).

[6] L. Zhang, Z. Wang, Y. Jia, Mater. Sci. Eng. B 231, 1 (2018). 
[7] T. Liu, F. Li, A. Wang, L.Xie, Q.F. He, J. Luan, A. He, X. Wang, C.T. Liu, Y. Yang, J. Alloys Compd. 776, 606 (2019).

[8] M. Nabiałek, B. Jeż, Eur. J. Mater. Sci. Eng. 04, 121 (2019).

[9] B. Płoszaj, Eur. J. Mater. Sci. Eng. 05, 69 (2020).

[10] P. Vizureanu, M.C. Perju, D.G. Galusca, C. Nejneru, M. Agop, Metal. Int. 15, 59 (2010).

[11] M.C. Perju, P. Vizureanu, Rev. de Chim. 65, 694 (2014).

[12] D.C. Achitei, P. Vizureanu, M.G. Minciuna, A.V. Sandu, A. Buzaianu, D.I. Dana, Mater. Plast. 52, 165 (2015).
[13] M. Nabiałek, S. Walters, P. Vizureanu, M.M.A.B. Abdullah, B. Jeż, Acta Phys. Pol. A 138, 152 (2020).

[14] M. Nabiałek, B. Jeż, K. Jeż, K. Błoch, Rev. de Chim. 70, 224 (2019).

[15] M. Nabiałek, B. Jeż, K. Błoch, Metall. Mater. Trans. A 51, 4602 (2020).

[16] S. Hasani, P. Rezaei-Shahreza, A. Seifoddini, Metall. Mater. Trans. A 50, 63 (2019).

[17] P. Rezaei-Shahreza, A. Seifoddini, S. Hasani, J. Non-Cryst. Solids 471, 286 (2017).

[18] T. Holstein, H. Primakoff, Phys. Rev. 59, 388 (1941). 